\title{
Fabrication of High Performance Fe-Si-Al Soft Magnetic Composites
}

\author{
You Junhua ${ }^{1^{*}}$, Li Qingda² and Qiu Keqiang1 \\ ${ }^{1}$ School of Materials Science and Engineering, Shenyang University of Technology, \\ ${ }^{2}$ College of Engineering, Heilongjiang Bayi Agricultural University,
}

China

\section{Introduction}

Soft magnetic composites (SMC) offers several advantages over traditional soft magnetic materials, for example, new shaping possibilities opens up for 3D design, very low eddy current loss, high magnetic permeability, high resistivity and low coercivity[1]. In recent years, effect of particle size, magnetic particle content, compaction parameters and annealing parameters on properties of soft magnetic composites has been verfied[2-6], and some theoretical works have been studied[7,8]. The conventional Fe-Si-Al (sendust) alloys are known to have several advantages, which include magnetostriction of 0 , anisotropy constant of 0 , higher electrical resistance, high permeability and lower cost $[9,10]$. The soft magnetic composites fabricated with $\mathrm{Fe}-\mathrm{Si}$-Al powder have a higher performance-cost and have a quick rising output all over the world. But few published information can be found about Fe-Si-Al soft magnetic composites.In this study, the effect of shaping pressure, annealing tempreture, magnetic annealing and dielectric content on properties of Fe-Si-Al soft magnetic powder cores was investigated. Through experimental optimization, the optimum process parameters were obtained.

\section{Experimental}

The Fe-Si-Al powder containing $85 \% \mathrm{Fe}, 9.6 \% \mathrm{Si}, 5.4 \% \mathrm{Al}$ was fabricated by water atomization method. The average particle size was about $72 \mu \mathrm{m}$. The dielectric was mica powder and average particle size was about $26 \mu \mathrm{m}$. A high temperature silicone adhesive was selected as binder. The powder mixtures of Fe-Si-Al and mica were mixed in bed with spiral mixer with continuous addition of $3.5 \%$ silicone adhesive and solution in ethanol solvent. After the evaporation of the solvent, the coated powder was obtained. Following drying, the coated powder was filled into die. Toroidal shape Fe-Si-Al powder cores (outer diameter $=27 \mathrm{~mm}$, inner diameter $=14.6 \mathrm{~mm}$, high $=11.75 \mathrm{~mm}$ ) were uniaxially cold compacted and kept for 6min. Annealing was carried out at Ar atmosphere for $60 \mathrm{~min}$, and then air cooling. Schematic view of magnetic annealing are shown in Fig.1. Copper bar connetced with power supply of low voltage and DC, and received electric current of $100 \mathrm{~A}$ in $15 \mathrm{~min}$. An overview of process parameter and fabricating methods is given in Table 1.

Scanning electron microscopy (SEM) and metallographic microscope (OLYMPUS GX71) were used to characterize the interior structure and morphology of specimens. The 
permeability and loss of the Fe-Si-Al powder cores were measured using a B-H analyzer (IWATSU SY-8232).Computer controlled materials tester was used to measure radial crushing strength (RCS) of specimens. The density of specimens was determined by the principle of Archimedes.

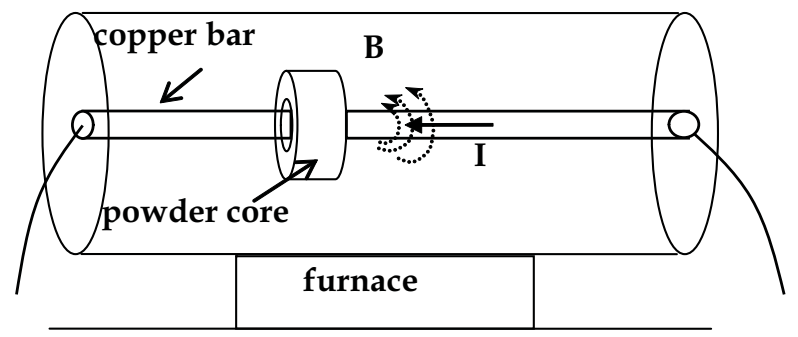

Fig. 1. Schematic view of magnetic annealing

\begin{tabular}{|c|c|}
\hline Series No. & $\begin{array}{l}\text { Shapine pressure }(\mathrm{MPa}) / \text { annealing tempertu } \\
\text { /time/annealing method/dielectric content }\end{array}$ \\
\hline 1 & $\begin{array}{l}\text { SP/660 }{ }^{\circ} \mathrm{C} / 1 \mathrm{~h} / \mathrm{annealing} / 0.7 \% \\
S P=1000,1200,1400,1600,1800,2000 .\end{array}$ \\
\hline 2 & $\begin{array}{l}\text { 1800/AT/1h/annealing } / 0.7 \% \\
\text { AT }=570,590,610,630,640,650,660,680,720 . \\
1800 / 660^{\circ} \mathrm{C} / 1 \mathrm{~h} / \text { annealing } / 0.7 \% \\
1800 / 660^{\circ} \mathrm{C} / 1 \mathrm{~h} / \text { magnetic annealing } / 0.7 \%\end{array}$ \\
\hline 3 & $\begin{array}{l}\text { 1800/660 }{ }^{\circ} \mathrm{C} / 1 \mathrm{~h} / \text { annealing/DC } \\
\mathrm{DC}=0.4 \%, 0.7 \%, 1.0 \%, 1.3 \%, 1.6 \% .\end{array}$ \\
\hline
\end{tabular}

$\mathrm{SP}$ - shapine pressure, AT - Annealing temperture, DC-dielectric content.

Table 1. An overview of process parameters and fabricating methods.

\section{Results and discussion}

Compaction is an important process in fabricating soft magnetic composites, and the appropriate compaction parameters is a necessary condition to produce high-performance soft magnetic composites. The effect of shaping pressure on density, coercivity, total loss and RCS (radial crushing strength) is given in Fig.2.

We have measured the RCS using equation as following[11]:

$$
\mathrm{RCS}=\mathrm{P}(\mathrm{D}-\mathrm{h}) / \mathrm{bh}^{2}
$$

where $\mathrm{D}$ is the outer diameter of sample, $\mathrm{h}$ the high of sample, $\mathrm{b}$ the thickness of sample and $\mathrm{P}$ is crushing load. Fig. 2 shows that density and RCS increase with increasing shaping 


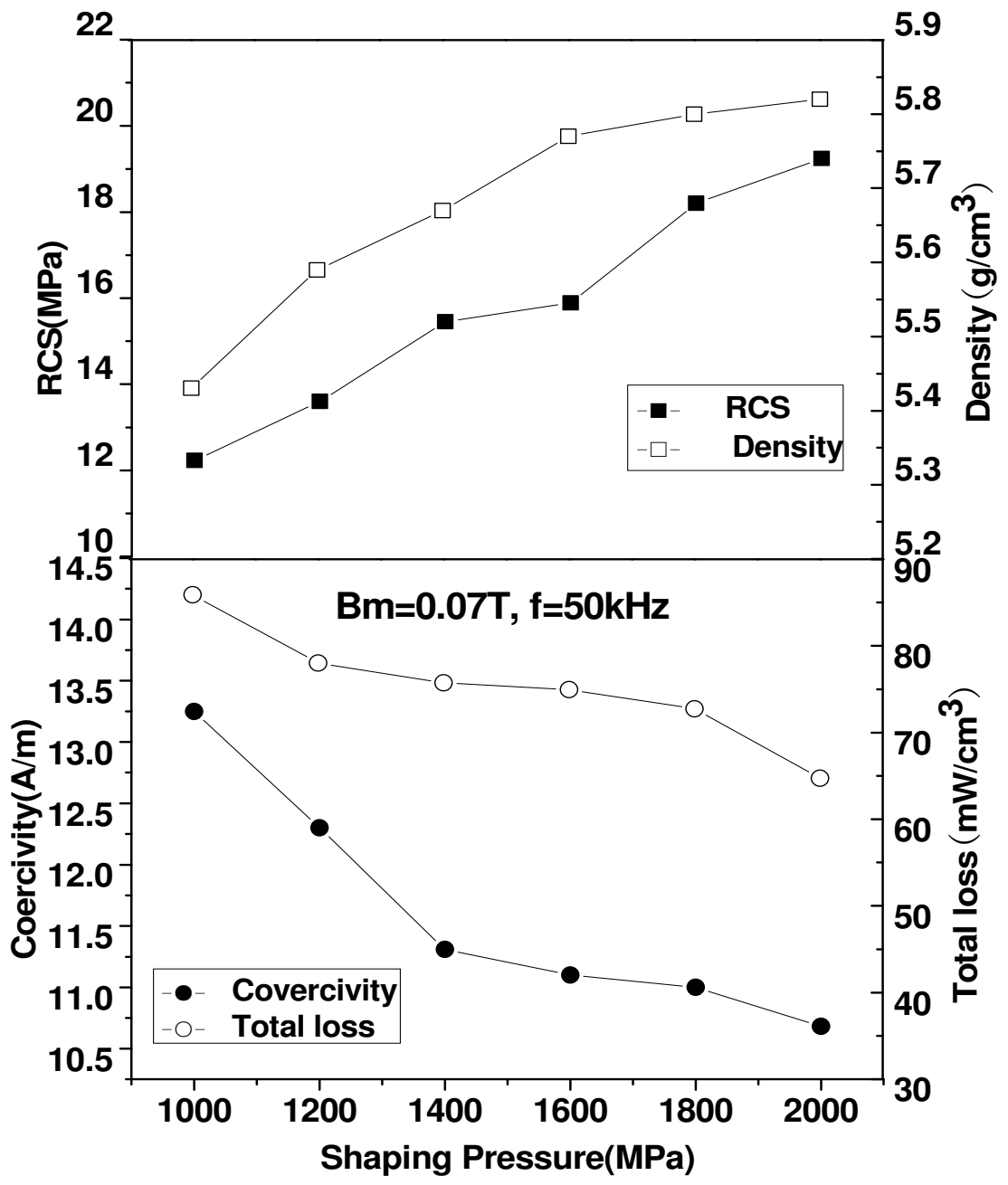

Fig. 2. The effect of shaping pressure on density, coercivity, total loss and radial crushing strength (RCS)

pressure. For SMCs spencimens made by powder metallurgy processes, pores were stress concentration centers and higher porosity (lower density) decreased the mechanical strength of specimens. By increasing shaping pressure, the porosity can be decreased and RCS can be improved[4]. Fig.3 shows the metallographic photos of Fe-Si-Al magnetic powder cores in different shaping pressure. It is found that porosity of specimen compacted by $1800 \mathrm{MPa}$ is lower comparing the specimen compacted by $1200 \mathrm{MPa}$. Fig.2 also shows that total loss and coervicity decrease with increasing shaping pressure. The behavior of coercivity of Fe-Si-Al magnetic powder cores can be explained by following equation[3]:

$$
\mathrm{H}_{\mathrm{c}}(\mathrm{x})=\mathrm{H}_{\mathrm{c}}(0)[1-\mathrm{x}]
$$


with the coercivity $\mathrm{H}_{\mathrm{c}}(0)$ at a magnetic particle content against zero and $\mathrm{H}_{\mathrm{c}}(\mathrm{x})$ the coercivity at filler fraction $x$. It is well known that increasing shaping pressure decreases amount of porosity and further increases $x$. According to equation (2), the coercivity of Fe-Si-Al magnetic powder cores was decreased by increasing shaping pressure. Generally, the high coercivity can induce the high loss for soft magnetic material[4]. So, total loss and coercivity present similar trend with increasing shaping pressure.


Fig. 3. Shows The metallographic photos of Fe-Si-Al magnetic powder cores in different shaping pressure

Variation of the complex magnetic permeability $\left(\mu^{\prime}\right.$ and $\left.\mu^{\prime \prime}\right)$ with frequency in different shaping pressure, for a maximum flux density of $0.07 \mathrm{~T}$, is shown in Fig.4. We can see that up to $50 \mathrm{kHz}$ the real part of permeability does not present a significant decrease. This fact suggests that the limiting frequency for these soft magnetic materials comes up to $50 \mathrm{kHz}$.


Fig. 4. Variation of the complex magnetic permeability $\left(\mu^{\prime}\right.$ and $\left.\mu^{\prime \prime}\right)$ with frequency in different shaping pressure, for a maximum flux density of 0.07 T. ("1000" indicates that powder core was compacted by $1000 \mathrm{MPa}$ ) 
Seen from Fig.4, the real part of permeability increases with increasing shaping pressure, reaches a peak value, and then decreases. In practice, high permeability can be achieved by high density. But, high density need high pressures[1], and higher pressure would introduce dislocation into the sample, thus create areas that can pin Bloch wall movement[12]. For this series, all samples had the same annealing temperature $\left(660^{\circ} \mathrm{C}\right)$, and the sample compacted by over-1800 MPa did not have a good stress release, and hence domain wall movement was impeded, and the real part permeability fell. So, selecting appropriate shaping pressure is very important to produce high-performance Fe-Si-Al soft magnetic powder cores, and the specimen compacted by $1800 \mathrm{MPa}$ presented the better properties.

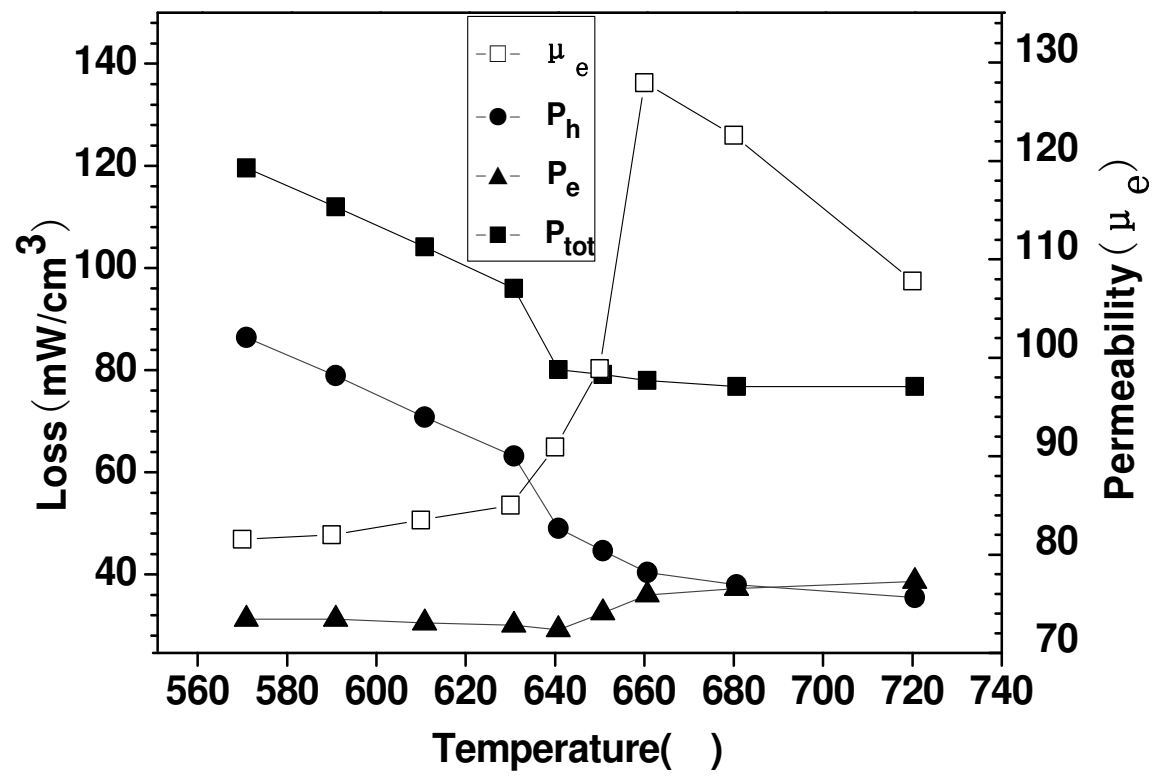

Fig. 5. The effect of annealing temperature on loss and effective permeability, for a maximum flux density of $0.07 \mathrm{~T}$, and frequency of $50 \mathrm{kHz}$.

In series 2, the annealing treatment of Fe-Si-Al magnetic powder cores was researched. In order to produce magnetic powder cores compressed, high pressure should be applied. The internal stresses which have been induced during compaction can deteriorate magnetic properties. Therefore, annealing treatment for reducing internal stresses is essential[6]. Fig. 5 shows the effect of annealing temperature on loss and effective permeability, for maximum flux density of $0.07 \mathrm{~T}$ and frequency of $50 \mathrm{kHz}$. It can be seen that total loss $\left(\mathrm{P}_{\text {tot }}\right)$ and hysteresis loss $\left(\mathrm{P}_{\mathrm{h}}\right)$ decrease, the eddy current loss $\left(\mathrm{P}_{\mathrm{e}}\right)$ does not present marked change with increasing annealing temperature. In addition, the effective permeability increases and reaches a maximum of 127 at $660{ }^{\circ} \mathrm{C}$ and then decreases with increasing annealing temperature. During compaction, internal stresses are generated in the materials. When the magnetic powder cores were magnetized in AC magnetic fields, the internal stresses impeded domain wall movement, and then led to decrease permeability and increased hysteresis loss and coercivity. The annealing treatment following the compaction can 
effectively relieve stresses, and so reduces hysteresis loss and increased permeability. Generally, the higher annealing temperature, the better stress relief, but the overannealing $\left(>660{ }^{\circ} \mathrm{C}\right)$ can degrade the insulation between powder particles and increase amount of porosity, thus increases the presence of eddy currents and decreases permeability. Fig.6 shows SEM image of Fe-Si-Al magnetic powder core at $720^{\circ} \mathrm{C}$ annealing. It can be seen that some insulation have been ablated and some voids in interior of Fe-Si-Al magnetic powder core are presented. From above research, increasing annealing temperature can decrease hysteresis loss of Fe-Si-Al magnetic powder cores and increase effective permeability.

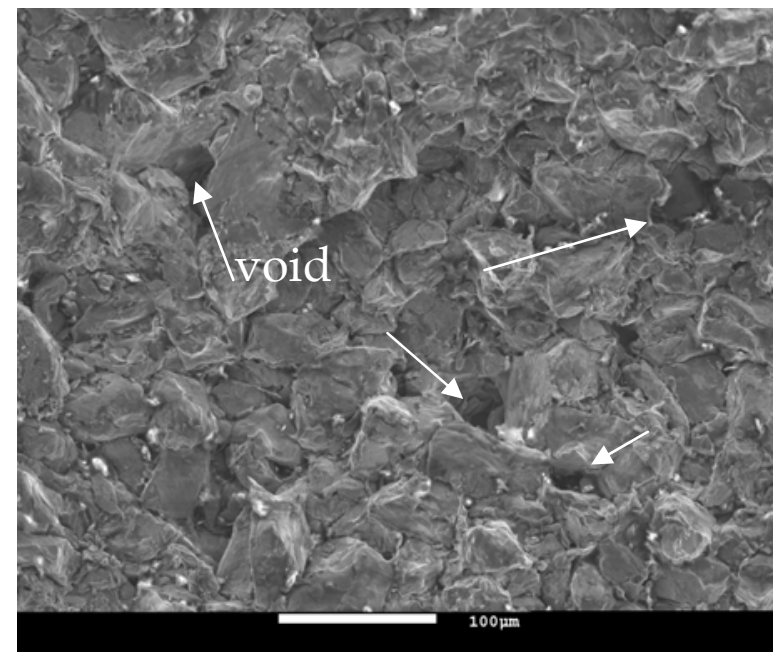

Fig. 6. SEM image of Fe-Si-Al magnetic powder core at $720^{\circ} \mathrm{C}$ annealing.

Fig.7 shows the variation of effective permeability and total loss with frequency in magnetic annealing and annealing, for a maximum flux density of 0.07T. It is clear that total loss increases with increasing frequency. It is well known that core loss is mainly composited of hysteresis loss and eddy current loss. Hysteresis loss varies linearly with frequency while current eddy loss veries with the square of the frequency[13]. Otherwise, Fig.7 shows that total loss of magentic powder core in magnetic annealing is smaller than that in annealing state, and the effective permeability of two annealing states don't present marked difference. Also, this loss factor in the magnetic annealing state is smaller than that in annealing state. The reasons for reduction in total loss of the sample with magnetic annealing may be explained by improved crystallinity[14]. In the present magnetic field, magnetic domains will be larger and domain growth will be easier[6]. In addition, magnetic moments of atomic pair forming are forced to orient along the magnetic field direction by magnetic annealing, and this behavior also improves the magnetic properties of $\mathrm{Fe}-\mathrm{Si}-\mathrm{Al}$ alloys. The behavior of Fe-Si-Al magnetic powder cores in magnetic annealing haves some difference to H.Shokrollahi's report, which magnetic annealing has influence on the effective permeability [6]. But this behavior of $\mathrm{Fe}-\mathrm{Si}$-Al magnetic powder cores is similar to $\mathrm{Fe}-\mathrm{Si}$ alloys, which magnetic annealing only reduces the loss of Fe-Si alloy[15]. So the addition of $\mathrm{Si}$ is a main reason which effective permeability of Fe-Si-Al magnetic powder core with magnetic annealing did not present marked difference comparing annealing. 


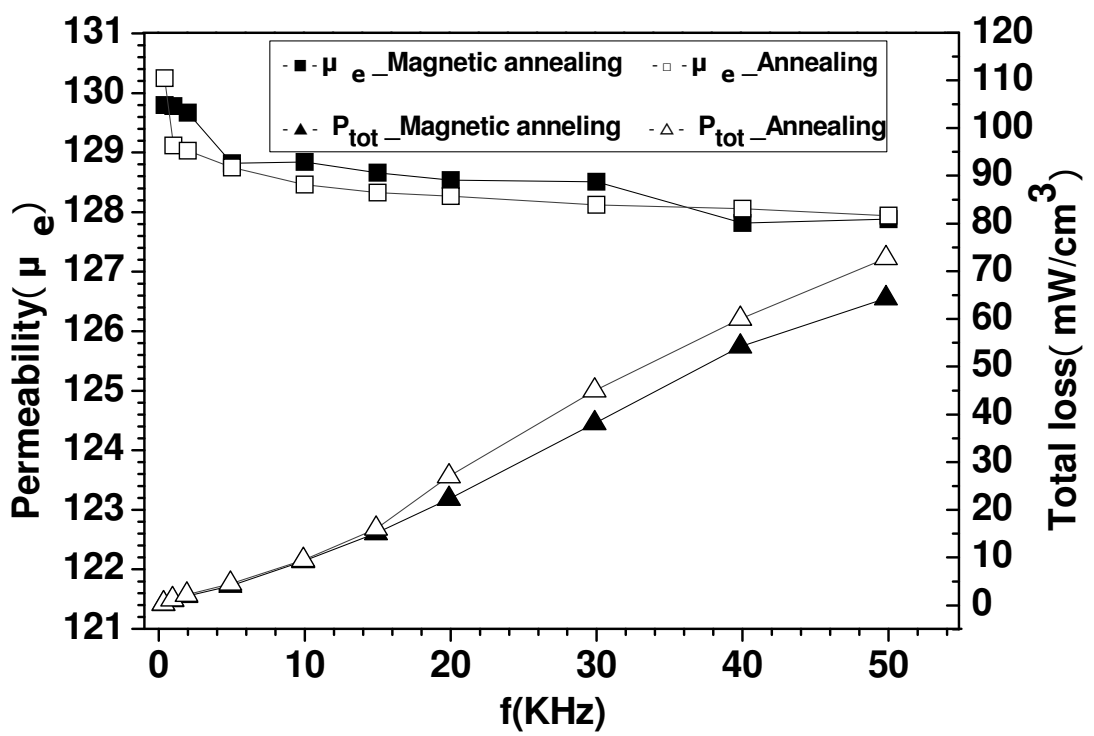

Fig. 7. Variation of effective permeability and total loss with frequency in magnetic annealing treatment and annealng, for a maximum flux density of $0.07 \mathrm{~T}$.

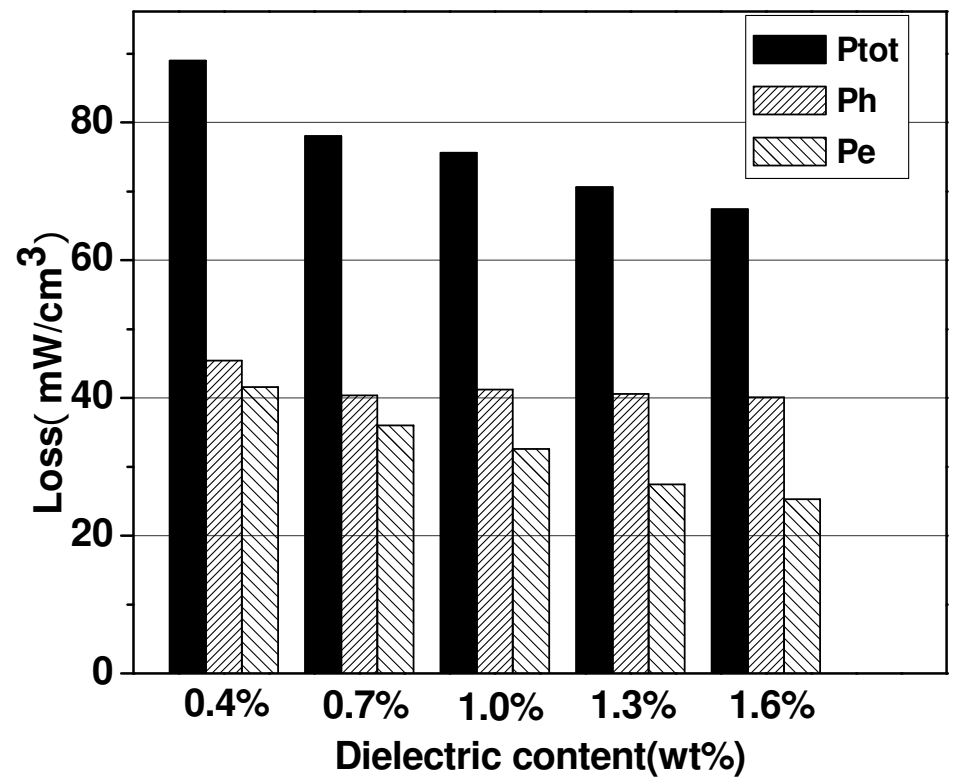

Fig. 8. The effect of dielectric content on total loss (Ptot), hysteresis loss (Ph) and eddy current loss $(\mathrm{Pe})$, for a maximum flux density of $0.07 \mathrm{~T}$ and frequency of $50 \mathrm{kHz}$. 
The core loss of a magnetic device is known to consist of hysteresis loss, eddy current loss. Among these, eddy current loss is dominant in high-frequency range[16]. Eddy current loss comes from two source, the first is eddy current of interior of magnetic powder, which should be reduced by regulating alloy component and inner structure, and another is the eddy current of the interparticle, which should be reduced by coating magnetic powder with dielectric. In fabricating magnetic powder cores, the second method is effective. The effect of dielectric content on total loss, hysteresis loss and eddy currrent loss is presented in Fig.8. Total loss and eddy current loss decrease with increasing dielectric content. The core with an addition of $0.4 \%$ dielectric shows total loss of $89 \mathrm{~mW} / \mathrm{cm}^{3}$, and then total loss of core with an addition of $1.6 \%$ dielectric decreases to $67 \mathrm{~mW} / \mathrm{cm}^{3}$. This can be related to the reduction in eddy currents in specimens with dielectric by decreasing the inner-particle connetction. Eddy current loss is expressed as following:

$$
\mathrm{Pe}=\mathrm{CB}^{2} \mathrm{f}^{2} \mathrm{~d}^{2} / \rho
$$

where $\mathrm{C}$ is the proportionality constant, $\mathrm{B}$ is the flux density, $\mathrm{f}$ the frequency, $\rho$ the resistivity and $d$ is the thickness of the material[5]. Decreasing of eddy current loss is due to increasing resistance of Fe-Si-Al magnetic powder cores. Although increasing dielectric content can reduce the loss, it deteriorate permeability. Fig.9 shows that the real part of permeability decreases with increasing dielectric content. It is well known that the real part of permeability strongly depends on the density and magnetic particle content of magnetic powder core, and increasing dielectric content can reduce the density and magnetic particle content. So increasing dielectric content can decrease the real part of permeability.

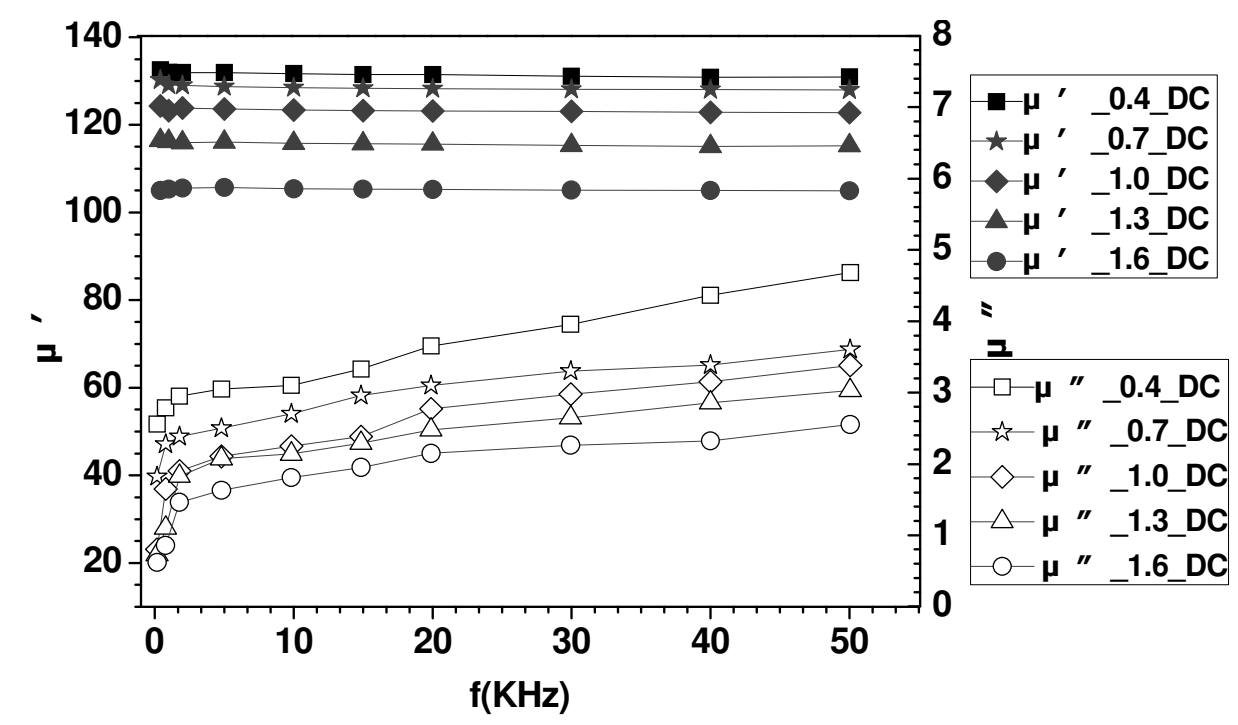

Fig. 9. Variation of the complex magnetic permeability $\left(\mu^{\prime}\right.$ and $\left.\mu^{\prime \prime}\right)$ with frequency in different dielectric content, for a maximum flux density of $0.07 \mathrm{~T}$ (“ $0.4 \_\mathrm{DC}$ ”. indicates that powder core contains $0.4 \mathrm{wt} \%$ of dielelctric content). 
In additon, Fig. 9 shows that the imaginary part of permeability decreases with increasing dielectric content. As we all know that the imaginary part of permeability reflects the loss of magnetic powder cores, and so the variation of the imaginary part of permeability in Fig. 9 accords with the variation of loss in Fig.8. The Fe-Si-Al magnetic powder core with dielelctric content of $0.7 \mathrm{wt} \%$ shows the better magnetic properties.

\section{Conclusion}

In this paper, the effect of shaping pressure, annealing tempreture, magnetic annealing and dielectric content on properties of Fe-Si-Al soft magnetic composites was investigated. The results showed that increasing shaping pressure can increase density and RCS of Fe-Si-Al soft magentic cores, and decrease coercivity and total loss. Annealing treatments can eliminate residual stresses and internal defects, and improve the magnetic properties of FeSi-Al soft magnetic composites. Increasing annealing temprature can increase effective permeability of specimens and decrease core loss owing to decreasing hysteresis loss. Overannealing $\left(>660{ }^{\circ} \mathrm{C}\right)$ can degrade the insulation between powder particles, and deteriorate magnetic properties. The magnetic annealing can decrease the total loss of Fe-Si$\mathrm{Al}$ magnetic powder cores comparing annealing. Increasing dielectric content can reduce the eddy current loss of Fe-Si-Al magnetic powder core and decrease the real part of permeability.

The Fe-Si-Al magnetic powder core with shaping pressure of $1800 \mathrm{MPa}$, annnealing temperature of $660{ }^{\circ} \mathrm{C}$ and dielelctic content of $0.7 \%$ presents the optimum magnetic properties with an effective permeability of 127 , a total loss of $78 \mathrm{~mW} / \mathrm{cm} 3$ and a radial crushing strength of $18 \mathrm{MPa}$.

\section{Acknowledgements}

This work are supported by the special foundation of Guangdong Province and Ministry of Education of China (Grant no. 2006D90404027) and 863 High Technical Project (Grant no. 2008AA03Z2472642).

\section{References}

[1] H.Shokrollahi, K.Janghorban, Mater. Sci. Eng B. 134 (2006) 41-43.

[2] M.Anhalt, J. Magn. Magn. Mater. 320(2008) e366-e369.

[3] M.Anhalt, B.Weidenfeller, J. Appl. Phys. 101 (2007) 023907.

[4] I. Hemmati, H. R. Madaah Hosseini, S. Miraghaei, Powder. Metall. 50 (2007) 86-90.

[5] H.Shokrollahi, K.Janghorban, J. Magn. Magn. Mater. 313 (2007) 182-186.

[6] H.Shokrollahi, K.Janghorban, J. Magn. Magn. Mater. 317 (2007) 61-67.

[7] J. L. Mattei, P. Laurent, O. Minot, M. Le Floc'h, J. Magn. Magn. Mater.160 (1996) 23-24.

[8] M. Anhalt, B. Weidenfeller, J. L. Mattei, J. Magn. Magn. Mater. 320 (2008) e844-e848

[9] M. Takahashi, S. Nishimaki, T. Wakiyama, J. Magn. Magn. Mater. 66(1987)55-62.

[10] R. A. McCurrie, Ferromagnetic Materials Structure and Properties, Academic Press, London, 1994, pp.48-77.

[11] W. X. Li, C. Y. Zhao, Z. M. Guo, S. Yin, J. Univ. Sci. Tech. Beijing. 22 (2000) 238-241.

[12] I. Gilbert, S. Bull, T. Evans, J. Mater. Sci. 39 (2004) 457-461. 
[13] L. P. Lefebvre, S. Pelletier, C. Gelinas, J. Magn. Magn. Mater. 176 (1997) L93-L96.

[14] D. A. Molodov, U. Czuayko, G. Gottstein, L. S. Shvindlerman, Acta. Mater. 46 (1998) 553-564.

[15] R.S.Tebble, D.J.Graik, Magnetic Materials, Wiley-Interscience, London, 1969, pp.536-537.

[16] Yoon B. Kim, D. H. Jang, H. K. Seok, K. Y. Kim, Mater. Sci. Eng. A. 449-451 (2007) 389393. 


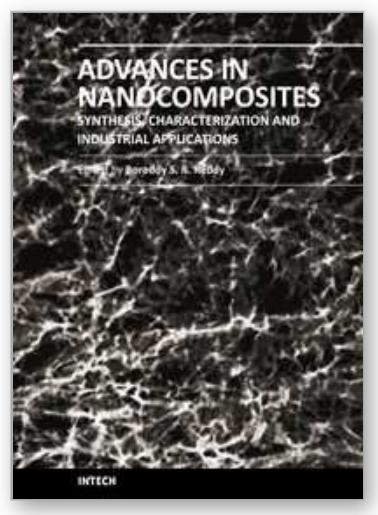

\author{
Advances in Nanocomposites - Synthesis, Characterization and \\ Industrial Applications
}

Edited by Dr. Boreddy Reddy

ISBN 978-953-307-165-7

Hard cover, 966 pages

Publisher InTech

Published online 19, April, 2011

Published in print edition April, 2011

Advances in Nanocomposites - Synthesis, Characterization and Industrial Applications was conceived as a comprehensive reference volume on various aspects of functional nanocomposites for engineering technologies. The term functional nanocomposites signifies a wide area of polymer/material science and engineering, involving the design, synthesis and study of nanocomposites of increasing structural sophistication and complexity useful for a wide range of chemical, physicochemical and biological/biomedical processes. "Emerging technologies" are also broadly understood to include new technological developments, beginning at the forefront of conventional industrial practices and extending into anticipated and speculative industries of the future. The scope of the present book on nanocomposites and applications extends far beyond emerging technologies. This book presents 40 chapters organized in four parts systematically providing a wealth of new ideas in design, synthesis and study of sophisticated nanocomposite structures.

\title{
How to reference
}

In order to correctly reference this scholarly work, feel free to copy and paste the following:

You Junhua, Li Qingda and Qiu Keqiang (2011). Fabrication of High Performance Fe-Si-Al Soft Magnetic Composites, Advances in Nanocomposites - Synthesis, Characterization and Industrial Applications, Dr. Boreddy Reddy (Ed.), ISBN: 978-953-307-165-7, InTech, Available from:

http://www.intechopen.com/books/advances-in-nanocomposites-synthesis-characterization-and-industrialapplications/fabrication-of-high-performance-fe-si-al-soft-magnetic-composites

\section{INTECH}

open science | open minds

\section{InTech Europe}

University Campus STeP Ri

Slavka Krautzeka 83/A

51000 Rijeka, Croatia

Phone: +385 (51) 770447

Fax: +385 (51) 686166

www.intechopen.com

\section{InTech China}

Unit 405, Office Block, Hotel Equatorial Shanghai

No.65, Yan An Road (West), Shanghai, 200040, China

中国上海市延安西路 65 号上海国际贵都大饭店办公楼 405 单元

Phone: +86-21-62489820

Fax: +86-21-62489821 
(C) 2011 The Author(s). Licensee IntechOpen. This chapter is distributed under the terms of the Creative Commons Attribution-NonCommercialShareAlike-3.0 License, which permits use, distribution and reproduction for non-commercial purposes, provided the original is properly cited and derivative works building on this content are distributed under the same license. 